\title{
How Strategic International Human Resource (IHR) Strategies can manage Organizational Performance Challenges
}

\author{
Dr. Rossano V. Gerald \\ D.B.A. (International Business) \\ American Public University System., Charles Town WV
}

\begin{abstract}
The global marketplace has become an economic reality in which the United States could be considered a dominant player, but some economists have stated that its position in this global economic environment has been declining in previous decades due to the European Union, Asian, and Emerging Markets. With that in mind, according to Wiley (1996) study, since the late 90s, most employers have been battling the benefits, conflicts, and challenges that come with a culturally diverse workplace. The advantage of a different environment is that it will bring about a broad range of knowledge, awareness, and viewpoints from people that were brought up in different cultural environments. As a result, a robust international position will require that human resource managers (HRM) are prepared to function effectively and efficiently in a goal-oriented environment. These managers must also appreciate cultural diversity and understand the complexities of the global climate and be willing to adapt their skills and strategies to cope with the international business challenges. This research paper will reveal how the GLOBE (Global Leadership and Organizational Behavior Effectiveness) techniques can be used to develop Human Resource Management Strategies to empower managers to do whatever is necessary to achieve organizational goals with the appropriate resources.
\end{abstract}

Keywords: International Human Resource (IHR), strategic HRM (SHRM) theory, and GLOBE.

\section{INTRODUCTION}

In the past decades, globalization had produced a surge of economic growth in emerging markets such as China, Brazil, South Korea, Mexico, and India. This economic growth has linked the human capital development process by focusing strategies of human resource management to address performance management plan concerns or challenges (Cascio, 2009). For example, Cannon study (1992) study has found that the performance management planning is part of the human resources (HR) process, in which managers could use to help them implement some strategic and organizational changes throughout their structure. In reflecting this author's defined term of this HR process, Cascio study (2009) said: "performance management requires [the] willingness, and commitment to focus on improving the performance level of the individual and team every day" (p.333). This author also said that there need to be three components that a manager must do well for this HR process to succeed. They are as followed: (1) Define performance by setting goals, measures, and assessment tools throughout the process. (2) Facilitating performance which consists of taking responsibilities for the performance task, to make sure that there is enough resource to complete the job and appropriately selecting the right qualified person for the job or task. (3) Encourage performance by recognizing and knowledge good performance with reward system but also promptly. As a result, global human resource managers must realize each different country culture, political-legal and how those environmental factors have influenced human resource policies and procedures in which it may require the human resource manager to adopt a flexible managerial approach to deal with international human capital challenges. For instance, a culturally (endorsed implicitly) theory of leadership styles (CLT) are often used to identify 
leaders' behaviors and attributes that are universally perceived as contribute to, or inhibit of outstanding leadership (House et al., 2004).

\section{CULTURAL LEADERSHIP THEORY (CLT)}

According to House et al. (2004), the GLOBE (Global Leadership and Organizational Behavior Effectiveness) which list six global CLT leadership dimensions that are a precursor to understanding different leadership styles (p.675):

1. Charismatic/Value-Based Leadership; It refers how leaders are inspiring, or motivating members to ensure that high performance is part of their core values.

2. Team Oriented Leadership; Team building techniques and values are implemented to ensure members achieve common goals.

3. Participative Leadership; It ensures that members are involved in the decision-making process.

4. Humane Oriented Leadership; It reflects on the leader's supportive and considerate aspects and their compassion and generosity towards society as a hold.

5. Autonomous Leadership; It refers to an independent and individualistic attribute of a leader.

6. Self-Protective Leadership; It defines how a leader is ensuring safety and security for individual or group member.

Country Ranking on Assertiveness:

\begin{tabular}{|l|l|l|}
\hline $\begin{array}{l}\text { Least Assertive Countries in } \\
\text { GLOBE }\end{array}$ & $\begin{array}{l}\text { Medium Assertive } \\
\text { Countries in GLOBE }\end{array}$ & $\begin{array}{l}\text { Most Assertive } \\
\text { Countries in GLOBE }\end{array}$ \\
\hline Japan/China & Mexico/Czech Republic & US/Canada \\
\hline
\end{tabular}

Country Ranking on Performance

\begin{tabular}{|l|l|l|}
\hline $\begin{array}{l}\text { Least Performance Countries } \\
\text { in GLOBE }\end{array}$ & $\begin{array}{l}\text { Medium Performance Countries } \\
\text { in GLOBE }\end{array}$ & $\begin{array}{l}\text { Most Performance } \\
\text { Countries in GLOBE }\end{array}$ \\
\hline Mexico/Czech Republic & Japan/China & US/Canada \\
\hline
\end{tabular}

Summary of CLT Leadership Cluster (House et al., 2004, p.684)

\begin{tabular}{|l|c|c|c|c|c|c|}
\hline $\begin{array}{l}\text { Societal } \\
\text { Cluster }\end{array}$ & $\begin{array}{l}\text { Charismatic/Value- } \\
\text { Based }\end{array}$ & $\begin{array}{l}\text { Team } \\
\text { Oriented }\end{array}$ & Participative & $\begin{array}{l}\text { Humane } \\
\text { Oriented }\end{array}$ & Autonomous & $\begin{array}{l}\text { Self- } \\
\text { Protective }\end{array}$ \\
\hline Anglo & High & Medium & High & High & Medium & Low \\
\hline $\begin{array}{l}\text { Latin } \\
\text { America }\end{array}$ & High & High & Medium & Medium & Low & Med/High \\
\hline $\begin{array}{l}\text { Eastern } \\
\text { Europe }\end{array}$ & Medium & Medium & Low & Medium & High/High & High \\
\hline $\begin{array}{l}\text { Confucian } \\
\text { Asia }\end{array}$ & Medium & Med/High & Low & Med/High & Medium & High \\
\hline
\end{tabular}

"Above table shows that U.S. and Canada (Anglo) are among the highest ranked countries on assertiveness and performance orientation. It is the middle range of all the other dimensions" (Hook, 2004, p.302). As a result, they should be pair up with nations that have below average CLT scores, but universal cultural orientation values.

Therefore, high Charismatic/Value-Based, Participative leaders and high Assertive cultural attributes such as (the U.S. and Canada) should be match up with medium Charismatic/ValueBased and Participative leaders, and below average Assertive cultural characteristics such as (Japan and China). There is less Performance culture attributes such as Mexico, and Czech 
Republic should be match up with (U.S. and Canada); because their Participative leadership (high) is positively correlated to Mexico and Czech Republic (high/medium) Charismatic/Value-Based and Team Oriented leadership style to ensure international collaborations.

These rankings indicate that nations with high Charismatic/Value-Based, Team-Orientated and Participative leadership styles should be involved in the delegation, consultation, normal, and everyday decision-making to ensure that objectives and responsibilities are defined which may be used to avoid cross-cultural communication conflicts among decision makers. For instance, in recent years, "the United States and Japan have initiated a series of Earthquake Policy Symposium and Forums. These meetings enable participants to share and develop common insights into earthquake research, disaster prevention, emergency, response, and long-term recovery and reconstruction" (Hook, 2004).

Therefore, understanding Cultural Values that drives these six nation's CLT leadership dimensions could be useful for developing a leader-follower relationship that relates to realworld situations and defines cross-cultural leadership's strengths and weakness to anticipate potential problem during an international rescue mission. By using this cross-cultural strategy and leadership formulation process; it ensures that high team integrative and high autonomous approach leadership styles will not be a subservient to each other societal and organizational cultural values, but instead create a more partnership atmosphere. As a result, human resource managers could use this team-goal orientation approach to reduce any uncertainty avoidance among critical players by implementing strategic HRM (SHRM) theory which could provide HR management practices to use in organizational strategic planning and achieve HR objectives (Raduan and Kumar, 2006).

\section{HR MANAGEMENT PRACTICES}

According to Raduan and Kumar (2006) study, "strategic HRM (SHRM) theory has often been used as a basic framework for the investigation of HR strategy and firm performance." One of the main discussions of this theoretical approach is whether an organization should develop their employment structure by using a competency approach that looks at the internal ("make") or external ("buy") sources to hire, train and develop their workforce. For example, "the "make" approach relies primarily on the internal development of critical HR, while the "buy" strategy emphasizes the acquisition of such competencies via the external labor market. Several relevant methods of the "make" strategy include selective recruiting, extensive training, promotion from within, and long-term attachment mechanisms" (Raduan \& Kumar, 2006).

However, many scholars have found that the internal development process has many desirable outcomes, which includes higher stability and predictability in operating the IHR because it can help in aggregating better coordination and control for managers in the foreign location. On the other hand, this internalization may come high significant costs when applying a universalistic or configurationally rather than contingency approach to the SHRM process.

This contingency theory approach requires that a business adopt their HR policies and practices to specific organizational strategy. As a result, for it to be useful in this industry, then the company's IHR policies must have procedural aspects which consistent with the domestic HR. By doing so, this company can elicit for employees that will more adapt to accept the overall organization's strategy. For example, past HR research in the Asian market, such as in Japan, the researchers have found that employee-based HR knowledge practice approach was 
used to motivate productive employee behavior to meet the company's production needs and achieve their business strategy's goals or objectives (Raduan \& Kumar, 2006).

According to Mahapa (2013) study, some factors can motivate an organization to establish formal and systematic management of information. [They are as followed]. The need to get a better insight on how the business works. [It can] reduce the time and effort in searching for information and documents. [It can] avoid repetition of errors and unnecessary duplication of work. [It also can] reduce the response time to questions [which] are frequently asked [to] improve the quality and speed of making important decisions.

This management of information is often referred as the Knowledge Management (KM) strategy, which is mostly focused on the storing and sharing of insights, understanding, and the expertise needed for organization workers to exchanged viewpoints and information about their jobs to enhance organizational performance efforts in a positive way. This process has been known to turn up-to-date information into a strategic resource, which could create an everlasting productive learning environment. For example, "the hospitality industry where employees are reluctant to share their knowledge freely” (Mahapa, 2013).

Therefore, it can help an organization capture the relevant experience and knowledge, which can be accessible to the company's workers. Thus, it would allow the entire group to learn from each other within the individualistic or collectivistic format. Lastly, the KM process could help to reduce monitoring and redevelopment of the employee but also includes training policies and procedures to communicate the business strategy and goals. Also, it could effectively increase the collaboration and responsiveness, and increase productive and competitive advantage within its industry (Mahapa, 2013). However, it should be noted that when it comes to the knowledge, skills, and abilities (KSA) or the competency level of an employee regarding them offering quality performance in their given task or job (Safdar, Waheed \& Rafiq, 2010). Then, the KM theory could be used in seeking skilled recruits by using job analysis techniques. This job analysis process could be utilized employment management procedure to find all the right steps in identifying the occupational skills for employees in any marketplace (Glenn, 2011).

\section{HR JOB ANALYSIS PROCESSES}

According to Glenn (2011) study, the job analysis process has been an essential aspect of the production control techniques, which are used in American manufacturing practices. This process was able accurately to identify each occupation regarding its duties, instrument required, must methodology for the operation and the sequencing of the working conditions. However, it should be noted that HR researchers have found that cultural regions, such as Pakistan which is a border neighbor of India that job analysis practice has not yet thoroughly been tested but acknowledged as an acceptable practice to evaluate employee job performance (Safdar, Waheed, \& Rafiq, 2010).

It should also be stated that one of the primary purposes of the job analysis is gathered detailed information to assess business specification skills of a potential recruit for hire. As a result, the manager must apply some performance measuring techniques to determine if one relative job worth is different from the other. This measuring process is done by following these measuring principles. (1) The HR person must determine what element of the occupation is being measured, such as the entire work and classifiable portion of the work. (2) The HR rep must determine whether any point values will be assigned quantifiable to measure the amount of the work. (3) This HR person must also provide descriptive information how jobs are being 
estimated and against what another job criterion within its industry. These measuring systems could help in determining the underlying point structure, ranking, and classifying system for business analysis evaluation system (I-Wei, and Kleiner, 2002).

Additional information from I-Wei and Kleiner (2002) study found that the job analysis must follow the strict guidelines of process steps to identify significant needed employment skills. They are as followed: "(1) Identify and isolate the component tasks in a job. (2) Examine how tasks are performed. (3) Identify the main areas of responsibility. (4) Identify the personal demands which work makes on an individual incumbent" (p.77).

However, there are a couple of ways in which this work-study could be applied, such as using job description and specification format that covers main points of the skills for a specific job. Once one of these analyzing processes is determined, then the HR manager could use different to obtain this information. These methods are the conversation, watching, surveys, and significant occurrences in the recruiting life, and professional diaries. Although out of those analyst methods, the interview is considered the most amenable way to elicit information from a recruit about job qualification of the different elements of the business requirements (I-Wei, and Kleiner, 2002). This training application could be used by using behavior modeling approach, which is about learning facts and procedures. It could also help the trainees to pay attention to imitated behavior patterns and allows them to elaborate on the behavioral encounter in language, which is suitable for them (Cascio, 2009).

The previous mentioned analytical activities could be used to measure some recruit technical and managerial skills, which are a necessary criterion for a specific job. Therefore, the HR manager must emphasize some employee technical skills to determine their primary competence in past performance before obtaining a position with a company. In other words, the potential candidate must display the ability to know how to do the work and interact with other variables, which could affect their underline performance in accomplishing a task within the profession. For this reason, this company must be International Standard Classification of Occupations (ISCO), which is supported by the International Labor Organization (ILO) to measure the competency level of employee skills (Dowling \& Welch, 2005).

\section{HR MEASURING OF EMPLOYEE'S SKILLS}

According to Tijdens, De Ruijter \& De Ruijter (2012) study, International Standard Classification of Occupations (ISCO) measurement system has been adopted globally by many of the developed and undeveloped nations, as an occupational classification and statistical data of labor forces by using surveying techniques. This data inquiry could elicit analyzed by using occupational code variables, which can match skills and occupational projections in a specific area. These analyses would be able to identify the aggregation of a professional level within its skill concept of testing for an occupation measurement process.

In addition to the ISO system, the International Standard Classification of Skills and Competencies will be used as an additional measuring tool to serve both as statistical and practical tools. These devices would be able to use career counseling and skill matching approach, and performance competency evaluation approach to examine the existing area of classifications within education and functional component (Markowitsch \& Plaimauer, 2009). Around human resource management, this measurement system would use practical applications for statistical purposes with limited sets of taxonomic classifications, which could analyze diverging demands with an occupational field. It also would be designed in a userfriendly way in which the vocabulary would use formal language and technical terms to illuminate professional content and the scope of technical skill needed for that occupation for 
this multilingualism area. Therefore, it is believed that the International Standard Classification of Skills and Competencies could meet the employment measurement skill needs when it comes to international taxonomic classifications for this labor market (Markowitsch \& Plaimauer, 2009).

When looking at the competent workforce requirement in any marketplace, then the company must consider recent data on how well-trained with relevant skills are essential to the success of any business in the private or public sector. Therefore, it is imperative that employees can integrate their knowledge and skills into an organization's business process to determine a competency-based training approach (Naquin \& Holton II, 2006).

\section{HR COMPETENCY-BASED TRAINING APPROACHES}

According to Thompkins and Daly (1992) study that was cited in Naquin and Holton II (2006), peer-reviewed article, the employer could use the competency-based training to evaluate an employee's capability to perform or demonstrate of their occupational field. If an employee has accomplished the job, then no other training is required, but if not, additional training will be targeted towards a specific area of interest or attention. In accord to develop competency training system, job analysis must be completed first on the employee, which can identify what tasks are required for this person. Next, the HR manager must determine the skills, which should be performed for each job. Thus, the competency evaluation criterion is based on these skill sets. This evaluation measures will explain what degree or level at which a worker must show an efficient competency in their skill. This assessment instrument could be used in identifying the employee's skill gaps and thus training could be developed from this competency issues to target these skill gaps. Afterward, the employee is processed through the training and assessing program until they have reached the desirable level of competency for a specific job. This competency system could also be used for an interview evaluation and performance process as a mean of documenting and integrating evaluation system to validate the competency results (Naquin and Holton II, 2006).

In the past three decades, several scholarly studies have found that India's companies have taken a crack at the competency modeling system by implementing it their human resource management functions. Some of these companies have had successful modeling issues while others were not able to adapt their existing HR standards to the training and development program requirement. The modeling problems were associated with the applicability of competency when it comes to defining the behavior variables against the overall perceived accomplishment requirements (Sarkar, 013).

It should also be mentioned that the competency-based/model can be seen stimulating learning environment in which a combination of information presentation and simulation methods or on-the-job training are needed to teach and coach the trainees. For example, Information-presentation techniques would be used to provide some lecture, and intranet and Internet training. Then, there are simulation techniques that are associated with the behavior modeling in which case method and role-playing sessions could be applied. Lastly, the on-thejob training methods would allow this company to use performance management, which includes the orientation training, and the near-the-job training and the on-the-job coaching (Cascio, 2009). Those stimulating learning techniques will be assessed by using these following measuring criterions in Naquin and Holton II study (2006, p.152). They are as follows:

(a) Employees' knowledge and skills are certified through competency-testing rather than credits (courses) taken. 
(b) Competency-based training is centered on behaviorally stated and measurable objectives.

(c) Trainee assessment or evaluation of learning is criterion-referenced rather than normreferenced.

(d) Assessments can take the form of written exams, oral exams, or skill practice demonstrations.

(e) In the event of failure, trainees could retake competency-based tests.

(f) Trainees receive immediate feedback on assessments.

(g) Various forms of media are used in the instructional process to meet trainees' individual learning needs.

This behavioral evaluation approach would probably be used in a formative process that takes place during the feedback sessions of any training assessment period after a different encounter between the trainer and the trainee (Broquet \& Punwani, 2012). According to Broquet and Punwani (2012) study, these authors stated, "feedback is reciprocal" in a welloiled performance feedback system. In fact, the aim for performance feedback system is to give managers detailed data and information on the performance processes. It could also help the manager to distinguish the messenger "noise" from "real problems of an individual competency level (Cipriano \& F. S., 2000). For example, the performance feedback results can identify the employee's job analysis and job description findings, which are associated the job goals and standards that were established as measuring performance criteria in a specific region or market to keep up with global HR strategic planning practices (Dowling \& Welch, 2005). For that reason, the researcher will describe the best strategic planning practices that can be used to scan internal and external environment by analyzing existing the effectiveness of the industry standards which are based on performance management. Then, this section will also discuss the resourcing strategies that should be used to determine the resources required to implement an HR strategic plan.

\section{HR STRATEGIC PLANNING PRACTICES}

Human resource managers must prepare employees for any global challenges by using strategic planning skills. This HR managerial tactic would improve the employee's conceptual and analytical skills, which would give them a competitive edge in the international business arena (Mathis, Jackson, \& Valentine, 2014). For example, strategic human resources management practices are macro-oriented, proactive and long-term focused on human capital as an asset or investment, not an expense. The strategic human resources management practices are also associated with organizational performance and concentrate on the alignment of human resources with firm strategy as a mean of gaining competitive advantage (Nee \& Khatri, 1999). This decision-making tactic could be used to strengthen and detect opportunities for organizations in which employee-based HR knowledge practice approach to determine potential candidates by using behavior interview assessment meets this company's needs and its goals achievement requirements (Raduan \& Kumar, 2006). For example, Dowling and Welch (2005) study found that technical and managerial skills are two of the main criteria when selecting a candidate for new hire. The ORC Worldwide 2002 survey validates this selection process found that up to 70 percent of the respondents have chosen candidates based on their skills or competencies for an occupation. In this same context, "hospitality multinationals committed to addressing...[these] HRM strategies which focus on selecting and training and developing global managers who understand the worldwide ramifications of their business and can operate efficiently around the world"(Dowling \& Welch, 2005, p. 98). With that in mind, the international HRM strategist should consider the resourcing methods on how people are recruited within the organization workforce. 
According to Armstrong (2016) study, "international resourcing strategy is based on workforce planning processes, which assess how many people are needed throughout the multinational company (demand forecasting), set out the sources of people available (supply forecasting) and, in the light of these forecasts, prepare actions plans for recruitment, selection or assignment (pg, 248)". Therefore, multinationals must focus on resourcing strategy that is addressing recruitment concerns from a global human resource perspective. For instance, the HRM strategist should concentrate on standardized recruiting systems that could adapt locally by using an external resourcing strategy. This HR strategy would consist comprehensive database recruitment criteria that address the candidate role descriptions within various professional-profile templates that are asking qualitative. However, also quantified questions that go beyond a persons' curriculum vitae which may be used to determine what are their cultural relations, language aptitudes; nations visited, and personal interests within hard and soft skills when it comes cultural and functional adaptability. Then, the strategy should contain a plan on how to obtain the right number and type of required recruits for defined professional skills and competencies by using recruitment process outsourcing (RPO) techniques, such as direct or indirect communication platforms, such as social media to recruit talent. The HR strategist should conduct quantitative research to get a better understanding of how to recruit diverse candidates, which would be used to determine what are the soft skills and cultural adaptabilities that the candidates have acquired to use as functional skills.

\section{METHODOLOGY}

The quantitative method was constructed to investigate IHR recruiting agencies selection process to understand the level of diversity and inclusion context that is configured in the selection of professional characteristics. This inquiry will also allow the investigation of employment and demographic trends in the Texas regions and Mexico metropolitan cities along the Southwestern borders. This method would also allow the research to participate in the statistical and summation analysis process by selecting the Generation $\mathrm{Y}$ and $\mathrm{X}$ candidates sampling size to ensure the candidates are in a multi-cultural setting. The quantitative research method also allows a significant sample data to be analyzed from various stand-alone computers and summarized into tabulation process. This descriptive approach will also be used to determine a confidence interval for the means with the unknown population standard deviation based on the recruiter questions about their soft skills and cultural adaptabilities.

\section{Hypothesis Questions}

For this study, the questions will be constructed to address recruitment effectiveness for a specific demographic. The hypothesis questions will be administrated to 25 recruiting agencies that are configured as a high-convergence organization in any industry. The main research questions are as follows: Hypothesis 1: Does the recruitment program has differentiation strategy that focuses on soft skills and cultural adaptability? Hypothesis 2: Are candidates' functional skills identified based on the cultural enjoyments? Hypothesis 3: Do recruits seem to show the attitude towards cultural learning purposefully? Hypothesis 4: What are some cultural adaptability questions that are used to probe for learning, enjoyment and purpose attributes? These questions will be analyzed by using triangulation method that will undertake an epistemological perspective to determine the positivist/postpositivist stance based on multiple linear regression analysis of the collected data, see Appendix for example with data results.

\section{Data Analysis Process}

The data collection process will consist descriptive research based on a hypothesis about means whereby primary and secondary documents will be used to allow the researcher to engage with HR recruiting agencies about respondents' soft skills and cultural adaptability 
during the recruitment period. A random sampling method will be used for this research, because of the various types of recruiting agencies in international regions but it would also allow the researcher to evaluate the organization's HRM procedures are adhere to Strategic International Human Resource Management (SIHRM). However, convenient sampling approach will be used to ensure that the labor force characteristics based on ethnicity, gender, and ages, see the below example.

\section{Labor force characteristics by race and ethnicity, 2015}

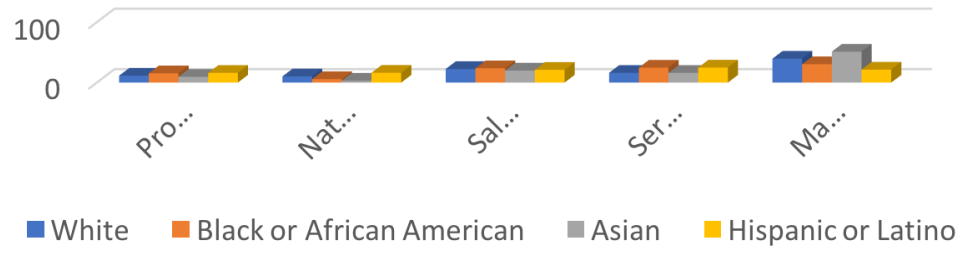

Figure 1 Labor Force Characteristics Graphic

The labor force characteristics are correlated to GLOBE tool when it comes to International Human Resource (IHR) program that would probably encourage human resource managers to apply the CLT leadership dimensions phases to discover what are the multi-cultural workforces that may give any entity a competitive advantage in the global working environment. Therefore, HR strategic planning structure should be constructed to contain GLOBE criterion that allows human resource managers to deal with International Labor recruitment challenges.

\section{CONCLUSION}

In conclusion, this researcher has convincingly shown that the GLOBE method is bested fitted for approach International Human Resource (IHR) strategy that must consist of strategic HRM (SHRM) theory to determine the best HR practice(s) when conducting job analysis but also measure of employees' skill sets. The researcher also explained how employment evaluation program should allow human resource managers to select candidates based on cultural diversity attributes. Then, the researcher addressed why and how competency-based training would also help to define behavior variables for specific technical requirements. Lastly, the researcher discussed which HR Strategic Planning Practices should be used with CLT leadership dimensions to help conduct International Performance Management Plan in resolving International Labor Laws challenges in any business market to achieve organizational strategies and goals.

\section{FUTURE RESEARCH RECOMMENDATION}

Future studies should be conducted on HR strategic plans for recruiting and selecting human resource managers in the overseas environment by using structured interviews in selecting and predicting employee performance for service industries (Sturman, 2003). The research would address the talent management related-oriented questions, which focuses on attraction and retention policies and programmes content to ensure that the organization has obtained and kept the right candidate based talent and GLOBE approach in the chosen market region. Thus, it can help to reduce any quasi-personality concerns in the candidate assessment.

\section{References}

Armstrong, M. (2016). Armstrong's Handbook of Strategic Human Resource Management; Sixth Edition. Kogan Page. 
Broquet, K. E., M.D., \& Punwani, M., M.D. (2012). Helping international medical graduates engage in effective feedback. Academic Psychiatry, 36(4), 282-7. Retrieved from

http://search.proquest.com/docview/1316088850?accountid=35812

http://search.proquest.com/docview/232360747?accountid=35812

Cannon, F. W. (1992). Performance management: A new perspective. Executive Development, 5(4), 11. Retrieved from

Cascio , W. F. (2009). Managing Human Resources. Productivity, Quality of Work Life, Profits, 9th ed. 1221 Avenue of the Americans, New York, N.Y. 10020: McGraw-Hill

Cummings, S. (1995). Pericles of Athens - Drawing from the essence of strategic Leadership. Business Horizons (January-February).

Cipriano Forza and, F. S. (2000). Assessing some distinctive dimensions of performance feedback information in high-performing plants. International Journal of Operations \& Production Management, 20(3), 359-385. Retrieved from

Evans, J. (2013). Statistics, data analysis, and decision modeling. (5th ed.). Upper Saddle River, NJ: Prentice Hall.

Dawson, M., Madera, J. M., \& Neal, J. A. (2011). Managing bilingual employees: Communication strategies for hospitality managers. Worldwide Hospitality and Tourism Themes, 3(4), 319-334.

doi:http://dx.doi.org/10.1108/17554211111162444

Dowling, P. J., \& Welch, D. E. (2005). International Human Resource Management 4th ed. Managing people in a multinational context. Mason, Ohio: Thompson South-Western.

Glenn, D. D. (2011). Job safety analysis: Its role today. Professional Safety, 56(3), 48-57. Retrieved from http://search.proquest.com/docview/855819522?accountid=35812

Kennett, D. (2004). Comparative Economics (2nd Ed.). 5191 Natorp Boulevard, Mason, Ohio 45040: SouthWestern.

http://search.proquest.com/docview/205864985?accountid=35812

Hooke, W. H. (2000). U.S. Participation in an international decade for natural disaster reduction. Natural Hazards

House, R. J., Hanges, P. J., Javidan, M., Dorfman, P. W., \& Gupta, V. (2004). Culture, leadership, and organizations (1st ed.). 2455 Teller Road, Thousand Oaks, California 91320: Sage.

Javidan, M., \& House, R. J. (2001). Cultural acumen for the Global Manager: Lessons from Project GLOBE. Organizational Dynamics, 29(4), 289-305.

Javidan, M., Stahl, G. K., Brodbeck, F., \& Wilderom, C. (2005). Cross-border transfer of knowledge: Cultural lessons form Project GLOBE. Academy of Management Executive, 19(2),

I-Wei, C., \& Kleiner, B. H. (2002). How to conduct job analysis effectively. Management Research News, 25(3), 7381. Retrieved from http://search.proquest.com/docview/223550988?accountid=35812

Mahapa, M. (2013). The impact of knowledge management strategies on organizational performance in the hospitality industry of Zimbabwe. Public Administration Research, 2(1), 76-83. Retrieved from http://search.proquest.com/docview/1439818177?accountid=35812

Maley, J. F. (2011). The influence of various human resource management strategies on the performance management of subsidiary managers. Asia - Pacific Journal of Business Administration, 3(1), 28-46. doi:http://dx.doi.org/10.1108/17574321111116388

Markowitsch, J., \& Plaimauer, C. (2009). Descriptors for competence: Towards an international standard classification for skills and competences. Journal of European Industrial Training, 33(8), 817-837. doi:http://dx.doi.org/10.1108/03090590910993652

Mathis, R. L., Jackson, J. H., \& Valentine, S. R. (2014). Human Resource Management. Stamford: Cengage Learning.

Naquin, S. S., \& Holton, Elwood F., I., II. (2006). Leadership and managerial competency models: A simplified process and resulting model. Advances in Developing Human Resources, 8(2), 144-165. Retrieved from http://search.proquest.com/docview/221206606?accountid=35812

Raduan, C. R., \& Kumar, N. (2006). The influence of organizational and human resource management strategies on performance. Performance Improvement, 45(4), 18-24, 48. Retrieved from

http://search.proquest.com/docview/237245230?accountid=35812 
Safdar, R., Waheed, A., \& Rafiq, K. H. (2010). The impact of job analysis on job performance: Analysis of A hypothesized model. Journal of Diversity Management, 5(2), 17-36. Retrieved from http://search.proquest.com/docview/506643513?accountid=35812

Sarkar, S. (2013). Competency-based training needs assessment - approach in Indian companies. Organizes, 46(6), 253-263. doi:http://dx.doi.org/10.2478/orga-2013-0025

Tijdens, K. G., De Ruijter, J., \& De Ruijter, E. (2012). Measuring work activities and skill requirements of occupations. European Journal of Training and Development, 36(7), 751-763.

doi:http://dx.doi.org/10.1108/03090591211255575

Sturman, M. C. (2003). Utility analysis: A tool for quantifying the value of hospitality human resource interventions. Cornell Hotel and Restaurant Administration Quarterly, 44(2), 106-116. Retrieved from http://search.proquest.com/docview/209711069?accountid=35812

Wiley, C. (1996). Training programmes that equip managers to deal with a diverse workforce. Equal Opportunities International, 15(1), 22-31. Retrieved from http://search.proquest.com/docview/199602481?accountid=35812

Bureau of Labor Statistics (BLS) https://www.bls.gov/opub/reports/race-and-ethnicity/2015/home.htm\#chart3 


\section{Correlation Matrix}

\section{APPENDIX}

\begin{tabular}{|c|c|c|c|c|}
\hline & White & $\begin{array}{r}\text { Black or } \\
\text { African } \\
\text { American }\end{array}$ & Asian & $\begin{array}{l}\text { Hispanic } \\
\text { or Latino }\end{array}$ \\
\hline White & 1.000 & & & \\
\hline $\begin{array}{c}\text { Black or } \\
\text { African } \\
\text { American }\end{array}$ & 812 & 1.000 & & \\
\hline Asian & .988 & .831 & 1.000 & \\
\hline $\begin{array}{r}\text { Hispanic or } \\
\text { Latino }\end{array}$ & .463 & .789 & .468 & 1.000 \\
\hline & 5 & \multicolumn{3}{|c|}{ sample size } \\
\hline & $\begin{array}{l} \pm .878 \\
\pm .959\end{array}$ & \multicolumn{3}{|c|}{$\begin{array}{l}\text { critical value } .05 \text { (two-tail) } \\
\text { critical value } .01 \text { (two-tail) }\end{array}$} \\
\hline
\end{tabular}

\section{Regression Analysis}

$\begin{array}{rrrrr}\mathrm{R}^{2} & 0.977 & & \\ \text { Adjusted R } & 0.908 & \mathrm{n} & 5 \\ \mathrm{R} & 0.988 & \mathrm{k} & 3\end{array}$

Std. Error $3.643 \quad$ Dep. Var. White

ANOVA table

\begin{tabular}{rrrrrr}
\hline Source & $S S$ & $d f$ & $M S$ & $F$ & $p$-value \\
\hline Regression & 562.0852 & 3 & 187.3617 & 14.11 & .1927 \\
Residual & 13.2748 & 1 & 13.2748 & & \\
\hline Total & 575.3600 & 4 & & & \\
\hline
\end{tabular}

confidence interval

\begin{tabular}{|c|c|c|c|c|c|c|}
\hline variables & coefficients & std. error & $t(d f=1)$ & $\begin{array}{c}p- \\
\text { value }\end{array}$ & $\begin{array}{r}95 \% \\
\text { lower }\end{array}$ & $\begin{array}{r}95 \% \\
\text { upper }\end{array}$ \\
\hline & & & & & - & \\
\hline Intercept & 5.7786 & 12.5578 & 0.460 & .7254 & 153.7828 & 165.3399 \\
\hline Black or African American & -0.1132 & 0.5858 & -0.193 & .8784 & -7.5566 & 7.3301 \\
\hline Asian & 0.6700 & 0.2103 & 3.186 & .1936 & -2.0020 & 3.3419 \\
\hline Hispanic or Latino & 0.1545 & 0.9457 & 0.163 & .8969 & -11.8623 & 12.1713 \\
\hline
\end{tabular}

\section{Figure 2 Labor Force Characteristics Multiple Linear Regression}

